\title{
TUMOURS OF THE CAUDA EQUINA
}

\author{
THE PROBLEM OF DIFFERENTIAL DIAGNOSIS
}

\author{
N. B. KER, C. B. JONES \\ From Whittington Hospital, Highgate Hill, London
}

\begin{abstract}
A retrospective study of 32 patients with primary tumours of the cauda equina is presented. Most of the patients were initially diagnosed as having prolapsed intervertebral dises and treated accordingly. The correct diagnosis was eventually made, usually after a long delay, and confirmed by myelography.

Treatment consisted of laminectomy and excision of the tumour. Only one tumour was frankly malignant; all the remaining patients were relieved of their pain and the majority recovered completely. The exceptions were those patients with long-standing neurological deficits; this highlights the importance of early diagnosis and correct treatment before irreparable damage occurs.
\end{abstract}

Tumours of the cauda equina are an uncommon but nevertheless important cause of the "sciatic syndrome". At times it is quite impossible to differentiate, on clinical grounds alone, between a cauda equina tumour and a prolapsed intervertebral disc.

Myelography, preferably showing the whole spinal canal, is strongly recommended as a routine investigation before submitting a patient to spinal exploration, even in the presence of a typical lumbar disc syndrome. Moreover, it is suggested that patients with back pain, limited spinal movements and decreased straight leg raising, who do not respond to a reasonable trial of conservative treatment, also should undergo myelography, even in the absence of abnormal neurology.

\section{PATIENTS}

Thirty-two patients with tumours of the cauda equina were retrospectively reviewed. Sixty per cent had first been seen in orthopaedic and rheumatology clinics but were eventually referred to neurosurgical centres. There were 21 men and 11 women; their average age was 38 years (range 8 to 78 years). The average duration of symptoms was 39 months; it was much less ( 27 months) in those patients with abnormal neurological signs and more (69 months) in those without.

Presenting features. Pain was by far the commonest cause of presentation and was absent in only two cases (Table I). Low back pain $(31 \%)$ and back pain with unilateral sciatica $(34 \%)$ were predominant. Bilateral sciatica was

N. B. Kerr, FRCS Ed. Senior Registrar

Royal National Orthopaedic Hospital. Brockley Hill, Stanmore, Middlesex HA7 4LP, England.

C. B. Jones, FRCS, Senior Registrar

Westminster Hospital, Dean Ryle Street, London SWIP 2AP.

England.

Requests for reprints should be sent to $\mathrm{Mr}$ N. B. Ker.

(C) 1985 British Editorial Society of Bone and Joint Surgery $0301-620 \mathrm{X} / 85 / 3085 \$ 2.00$
Table I. Presenting symptoms in 32 patients

\begin{tabular}{lll}
\hline Symptoms & Number & (\%) \\
\hline Back pain & 10 & 31 \\
Back pain and unilateral sciatica & 11 & 34 \\
Back pain and bilateral sciatica & 2 & 6.25 \\
Sciatica alone & 1 & 3 \\
Anterior thigh pain & 2 & 6.25 \\
Back pain and buttock pain & 1 & 3 \\
Sensory disturbance & 5 & 15.5 \\
\hline
\end{tabular}

noted initially in only two patients, but this number had increased to seven by the time of operation. Sciatica without back pain was reported in one case. Two patients presented with "hip" and anterior thigh pain, and one with back pain radiating into the buttock. Sixteen patients $(50 \%)$ thus presented with some sort of leg pain, which, by the time of operation, had increased to 23 patients $(72 \%)$.

Five patients $(15.5 \%)$ presented with sensory disturbances; in three, there was an area of numbness in the foot, and in two, decreased perineal sensation.

Six patients $(19 \%)$ had noted increasing weakness in the legs. Two patients had noticed disturbances in bladder function, and by the time of operation two other patients complained of urinary symptoms. One patient presented with an 18-month history of progressive weakness and intermittent numbness of one leg not associated with pain; initially lumbar pain had been quite severe but had been "cured" by a faith healer.

In six patients $(19 \%)$ the onset of symptoms was sudden, following heavy lifting, a fall or a physical jolt. Most patients stated that movements, especially bending forward, increased their pain as did coughing, sneezing and lifting. Ten patients $(31 \%)$ suffered intermittent 
symptoms with periods of remission ranging from a few weeks to several years.

It is noteworthy that nine patients $(28 \%)$ had no abnormal neurological signs and that $12(37.5 \%)$ had only minor changes. The most consistent clinical findings were limitation of spinal movements (found in 23 patients) and decreased straight leg raising (SLR), in 19. This was true not only of the group as a whole but also of those patients with no abnormal neurology. Of these, eight out of nine had limited spinal movements and marked diminution of SLR which was bilateral in seven cases. In those with minor neurological changes, all had diminished SLR; in $60 \%$ of cases this was bilateral. In those cases with marked neurological changes, the SLR was diminished in $25 \%$, normal in $15 \%$ and not recorded in $60 \%$. All neurological signs at the time of operation are listed in Table II.

In 16 patients there was diminished response to pinprick in one dermatome only, or an area of numbness in the foot; in the rest, several dermatomes were affected and two patients had saddle hypoaesthesia.

Absent or diminished ankle jerks were demonstrated in 14 cases $(44 \%)$ bilaterally in three. In five cases $(15 \%)$, the knee jerks also were affected (three bilaterally). By the time of operation, weakness of specific muscle groups was noted in 14 cases $(44 \%)$; this was severe in 10. Two patients were so weak that walking was impossible; four others could not stand because of severe pain.

Diagnosis. Considerable delay in making the correct diagnosis was frequent; in all cases, it was eventually reached by myelography, as illustrated in Figures 1 and 2 . The cerebrospinal fluid protein level measured at the time of myelography was only available in 11 patients $(34 \%)$ but was markedly raised in all these.

Many patients had been diagnosed, not unreasonably, as having prolapsed intervertebral discs and had been treated with courses of physiotherapy and anal-

Table II. Signs at time of operation

\begin{tabular}{|c|c|c|c|}
\hline Signs & Number & $(\%)$ & Comments \\
\hline $\begin{array}{l}\text { Limited spinal } \\
\text { movements }\end{array}$ & 23 & 72 & $\begin{array}{l}\text { No record in } 8 \text { patients } \\
(25 \%)\end{array}$ \\
\hline Limited SLR & 19 & 60 & $\begin{array}{l}\text { Bilateral in } 13 \text { patients; } \\
\text { normal in } 3 \text { patients, } \\
\text { no record in } 10 \text { patients }\end{array}$ \\
\hline $\begin{array}{l}\text { Ankle jerk only } \\
\text { absent or diminished }\end{array}$ & 9 & 28 & Bilateral in 3 patients \\
\hline $\begin{array}{l}\text { Knee and ankle jerk } \\
\text { absent or diminished }\end{array}$ & 5 & 15 & Bilateral in 3 patients \\
\hline $\begin{array}{l}\text { Knee jerk only } \\
\text { diminished or absent }\end{array}$ & 3 & 15 & Bilateral in all 3 patients \\
\hline $\begin{array}{l}\text { Objective weakness } \\
\text { in specific muscle } \\
\text { groups }\end{array}$ & 14 & 44 & $\begin{array}{l}\text { Minimal in } 4 \text { patients; } \\
\text { marked in } 10 \text { patients }\end{array}$ \\
\hline Sensory disturbance & 14 & 44 & $\begin{array}{l}\text { Minimal in } 7 \text { patients; } \\
\text { marked in } 7 \text { patients }\end{array}$ \\
\hline
\end{tabular}

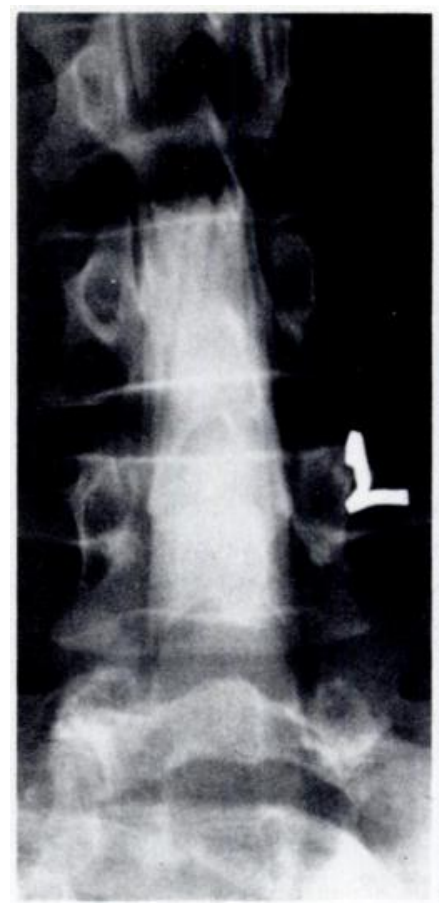

Fig. 1

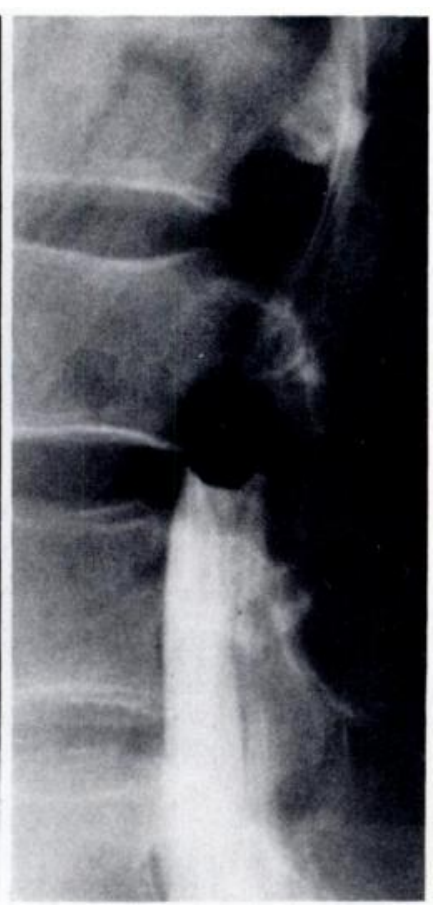

Fig. 2
A neurofibroma diagnosed by myelography. Figure 1-Anteroposterior view showing complete block to dye at L1/L2. Figure 2Lateral view of the same patient.

gesics; several were labelled neurotic and discharged from clinics. One patient had had an exploration for a prolapsed disc without pre-operative myelography; no disc was found. Another patient had undergone exploration of the sacro-iliac region for intractable pain. Three patients had undergone myelography which failed to show the lesions; one of these underwent exploration for a prolapsed disc and no lesion was found. Further myelography in these three cases and the initial myelography in all the other patients revealed the presence of a tumour.

Treatment. All the patients were treated by laminectomy and excision of the tumour where feasible. The tumours are listed in Table III. Only one tumour was frankly

Table III. Diagnosis in the 32 patients

\begin{tabular}{lc}
\hline Tumour & $\begin{array}{l}\text { Number of } \\
\text { patients }\end{array}$ \\
\hline Neurofibroma & 14 \\
Ependymoma & 11 \\
Haemangioblastoma & 2 \\
Astrocytoma & 2 \\
Lipoma & 1 \\
Epidermoid Cyst & 1 \\
Developmental cyst & 1 \\
Total & 32 \\
\hline
\end{tabular}


malignant, a mixed ependymoma/astrocytoma which behaved like a Grade III astrocytoma; this patient died two months after operation. Radiotherapy was utilised in the treatment of ependymomas only when indicated on histological grounds or when complete excision was impossible.

Apart from the patient with malignancy, all the patients recovered well. All 31 were relieved of their pain. Most recovered from any motor deficit, but not the two patients with very long-standing foot drop. Of the four patients with bladder dysfunction, three recovered completely, although recovery was protracted in two. The fourth patient died two months after operation.

\section{ILLUSTRATIVE CASE HISTORIES}

Case 1. A 40-year-old man developed low back pain of sudden onset in July 1979. His symptoms were intermittent and when he attended an orthopaedic clinic no abnormal neurological signs were noted and a diagnosis of lumbar disc degeneration was made. Physiotherapy was prescribed, but traction exacerbated his symptoms to such an extent that treatment was stopped. After several further consultations he was eventually discharged and referred to a psychiatrist.

In March 1980, he attended another orthopaedic clinic. At this time he complained of low back pain with radiation to the left thigh; the pain was exacerbated by deep breathing and by spinal flexion. Night pain. eased by sleeping in a chair, had been present for several months. Power and sensation were normal. Spinal movements were restricted and the left ankle jerk was diminished. A radiograph revealed degeneration of $\mathrm{L} 4 / 5$ and $\mathrm{L} 5 / \mathrm{S} 1$ intervertebral discs. A diagnosis of lumbar disc degeneration was made and a course of mobilisation instigated. Slight improvement with physiotherapy was noted.

In March 1982. he returned complaining of pain across the lower back, although he was still able to work. Spinal movements were almost full but there was apprehension on flexion. No neurological deficit was noted and a further course of physiotherapy was prescribed. In June 1982, the back pain and left leg pain increased significantly. Spinal movements were limited, straight leg raising was diminished and the left ankle jerk was absent. By July, the pain had increased; slight wasting of extensor digitorum brevis and an absent left ankle jerk were noted. Electromyograms showed SI root degeneration and he was referred to a "Problem Back Clinic".

In August 1982, he complained that the pain was predominantly in the left leg. Examination and assessment were now almost impossible because of pain. Myelography revealed a complete block at the level of L4. He was then referred to a neurosurgical centre. In September 1982. a laminectomy was performed and a neurofibroma excised. Postoperatively, all his pain was relieved, although spinal movements remained restricted.

Case 2. A 38-year-old woman presented to an orthopaedic clinic with low back pain and left sciatica. She also complained of intermittent numbness in the left buttock and occasional pain in the right leg. Reflexes and sensation appeared normal but straight leg raising was diminished bilaterally. A diagnosis of prolapsed intervertebral disc was made and treatment with physiotherapy started. This was unsuccessful and, after a period of bed rest, a myelogram was carried out. This suggested a prolapsed disc at L4/5, even though much of the dye was injected into the subdural space. In view of the rather inconclusive myelographic findings, it was decided to continue conservative treatment. Six months later the pain had increased to such an extent that, despite the absence of abnormal neurology, exploration was undertaken. No prolapsed disc was found.

Immediately after operation the pain was much improved. Over the next few weeks, however, the pain increased, the left buttock became numb, a left foot drop developed and retention of urine precipitated re-admission to hospital. A further myelogram revealed a com- plete block at the level of T12. She was referred to a neurosurgical centre where a laminectomy was undertaken and an ependymoma was excised. After the operation her pain was completely alleviated and the foot drop and bladder function returned to normal. However, the buttock sensation remains impaired.

\section{DISCUSSION}

The management of patients with back disorders involves many medical practitioners, especially those in orthopaedic and rheumatology clinics. The very high incidence of prolapsed intervertebral discs and other mechanical disorders tends to overshadow less common causes. Waddell (1982) states that 1.1 million patients consult their general practitioners with back problems; 800000 are then referred to a hospital specialist, 30000 are admitted to hospital and 5000 undergo surgery.

The incidence of primary intraspinal tumours is difficult to estimate with any accuracy. Waddell reports an incidence of $0.8 \%$ in a personal series of 900 patients with back pain. Craig et al. (1952) and Toumey, Poppen and Hurley (1950) report incidences of $4 \%$ and $4.3 \%$ in patients undergoing laminectomy for "sciatic syndrome." In the later stages there is little difficulty in diagnosing cauda equina tumours, as there is widespread neurological involvement of both lower limbs and often bladder dysfunction. Early diagnosis, however, is often much more difficult. These tumours are usually benign, and excision offers an excellent chance of full recovery provided prolonged pressure has not produced irreparable nerve damage. Unfortunately, diagnosis is often considerably delayed. In the present series, the average delay in diagnosis was 39 months and many authors report a similar period (Milnes 1953; Fearnside and Adams 1978; Cohen and Kaplan 1943). Patients are thus not only sentenced to long periods of useless conservative treatment but are also at risk of sustaining permanent neurological damage.

Allen's (1930) caution that "the stage of onset is the stage of errors" is certainly apposite in the diagnosis of cauda equina tumours. Early diagnosis is, however, diffcult: the presentation is varied and often the clinical picture is indistinguishable from a prolapsed intervertebral disc. Attempted classification of presenting symptoms seems to have little practical value.

In all the series we have reviewed, the predominant symptom was pain, usually back pain with or without root pain, although occasionally root pain alone is described. Intermittent pain, so commonly a feature of the lumbar disc syndrome, is not infrequently seen in cauda equina tumours, especially early in their history: indeed, $30 \%$ of our patients reported such symptoms. Allen (1930) reported a higher incidence of $90 \%$, and Love (1944) reported 84\%. Fearnside and Adams (1978) stated that in some cases pain fluctuated in intensity and tended to become constant and progressive. However, progressive unremitting pain should alert the clinician to the possibility of an intraspinal neoplasm. 
The mode of onset of symptoms is also of little help in distinguishing between prolapsed disc and neoplasm. In many patients with a cauda equina tumour the onset of symptoms is sudden; in $20 \%$ of the present series symptoms came on suddenly after strenuous muscle exertion. Love (1944) reports that $44 \%$ of spinal tumours present following trauma, and Stern (1978) reports similar findings.

An unusual distribution of pain, for instance anterior thigh pain in association with low back pain, should alert the clinician to the possibility of a cauda equina tumour. The development of bilateral sciatica is an absolute indication for myelography; if of sudden onset it may be due to subarachnoid haemorrhage from degeneration of a tumour (Falconer 1966).

Nocturnal pain is traditionally characteristic of cauda equina tumours. Dodge et al. (1951), Craig et al. (1952) and Fearnside and Adams (1978) report an incidence of approximately $50 \%$. In our series, $25 \%$ had night pain.

Limitation of spinal movements and straight leg raising were common, though not invariable, features in our series. The ankle reflex was diminished or absent unilaterally in $43 \%$, bilaterally in $9 \%$. This, however, is not an uncommon finding with lumbar disc problems. The knee jerks were absent in five patients, three bilaterally. However, all tendon reflexes were increased in one patient who had a lipoma affecting the conus and giving rise to upper motor neurone signs. A marked motor deficit was noted in 10 patients $(31 \%)$; three had foot drop, others had widespread weakness with muscle wasting. Four of these patients had bladder dysfunction. Bladder dysfunction generally tends to be a late manifestation, although by the time extensive neurological involvement is evident, retention of urine is relatively common (Cohen and Kaplan 1943). Garfield and Lytle (1970) reported three cases of cauda equina tumours presenting as problems of micturition: their patients denied any leg symptoms and there were no abnormal leg signs. The anal sphincters were lax, thus re-emphasising the importance of rectal examination in the assessment of patients with back pain.

Sensory disturbances are common with both prolapsed intervertebral discs and tumours. Extensive numbness is not usually found unless there is a large central disc protrusion or a well-established tumour compressing the cauda equina. In the present series 14 patients $(44 \%)$ had objective sensory changes; in half of this group, changes were limited to one dermatome while the others had more extensive involvement. Two had marked saddle hypoaesthesia. We conclude that involvement of several dermatomes in one or both limbs is a definite indication for further investigation.
It is important to stress that $66 \%$ of patients in our series had no neurological abnormalities or only minor ones. Other authors report similar findings (Kaplan, Bender and Sapirstein 1942; Cohen and Kaplan 1943; Dodge et al. 1951). This makes the early differential diagnosis difficult: in the later stages, however, widespread neurological damage becomes evident.

Myelography. In all our patients, the diagnosis was eventually made by myelography which invariably showed a complete block to the dye (Figures 1 and 2). Unfortunately, the results of the analysis of CSF taken at the time of myelography were available only for 11 patients, but were significantly abnormal in all. CSF protein may be slightly elevated with a prolapsed intervertebral disc, but a value of $100 \mathrm{mg} / 100 \mathrm{ml}$ or more should suggest a tumour, and is particularly important if the myelogram does not show the lower thoracic region.

In the early stages of cauda equina tumour, the diagnosis is almost entirely a laboratory and radiological procedure, as on clinical grounds alone it may be quite impossible to distinguish between a prolapsed disc and such a tumour. In view of this we take issue with Jepson, Nada and Rymaszewski (1982) who stated that, "Patients with a typical clinical picture of a lesion of a lumbar disc may be operated on with a low risk of negative exploration" and that, "There is little justification for the routine use of radiculography before operating for a lesion of a lumbar disc."

As we have shown, tumours of the cauda equina may present with a clinical picture typical of a lumbar disc lesion. The exposure for removal of a disc and decompression of a nerve root is not extensive and an unsuspected lesion is easily missed. Craig et al. (1952) stated that, "It is not unusual at this clinic to remove a spinal cord tumour from a patient who has had a previous operation for protruding disc without relief of symptoms." Should operation be undertaken and a tumour overlooked, the symptoms may be exacerbated. Minor surgical trauma can cause considerable swelling, leading to compression of the cauda equina and even acute paraplegia (Watkins, personal communication). We therefore believe that all surgical explorations of the spine, even in the presence of a typical clinical picture of a lumbar disc lesion, should be preceded by adequate myelography showing the lumbar canal, lower thoracic region and preferably the entire spinal subarachnoid space.

We should like to express our thanks to the following colleagues for allowing us to report their cases and for their help and encouragement in producing this article: $\mathrm{Mr} \mathrm{C}$. Connolly, Mr A. Crockard, Mr T. T. King, Mr D. F. Paton, Mr R. W. Rushman, Professor E. S. Watkins; and to Miss R. Burns for preparing the manuscripts. 


\section{REFERENCES}

Allen IM. Tumours involving the cauda equina: a review of their clinical features and differential diagnosis. $J$ Neurol Psychopath $1930 ; 11: 111-43$

Cohen I, Kaplan A. Tumors in the region of the cauda equina: review of 25 cases. Am J Surg 1943;60:36-43.

Craig WM, Svien HJ, Dodge HW Jr, Camp JD. Intraspinal lesions masquerading as protruded lumbar intervertebral discs. JAMA $1952 ; 149: 250-3$.

Dodge HW Jr, Svien HJ, Camp JD, Craig WM. Tumors of the spinal cord without neurological manifestations producing low back pain and sciatic pain. Proc Mayo Clin 1951;88-95.

Falconer MA. Problems in neurosurgery: cauda equina tumours. Trans Med Soc Lond 1966;82:126-38.

Fearnside MR, Adams CBT. Tumours of the cauda equina. J. Neurol Neurosurg Psychiatry 1978;41:24-31.

Garfield J, Lytle SN. Urinary presentation of cauda equina lesions without neurological symptoms. Br J Urol 1970;42:551-4.
Jepson K, Nada A, Rymaszewski L. The role of radiculography in the management of lesions of the lumbar disc. J Bone Joint Surg $[\mathrm{Br}]$ 1982;64-B:405-8

Kaplan A, Bender MB, Sapirstein M. Sciatic pain: its significance in the diagnosis of cauda equina tumors: report of four cases. $J$ Bone Joint Surg 1942;24:193-9.

Love JG. Differential diagnosis of intraspinal tumors and protruded intervertebral disks and their surgical treatment. $J$ Neurosurg 1944; 1 :275-90.

Milnes JN. Early diagnosis of tumours of cauda equina. J Neurol Neurosurg Psychiatry 1953;16:158-65.

Stem WE. Localization and diagnosis of spinal cord tumours. Clin Neurosurg 1978;25:480-94.

Toumey JW, Poppen JL, Hurley MT. Cauda equina tumors as a cause of the low-back syndrome. J Bone Joint Surg [Am] 1950; 32-A :249-56.

Waddell, G. An approach to backache. Br J Hosp Med 1982; 28: $187,190-1,193-4$. 